\title{
Particle size distribution and gas-particle partitioning of polychlorinated biphenyls in the atmosphere in Beijing, China
}

\author{
Qingqing Zhu ${ }^{1,2} \cdot$ Minghui Zheng ${ }^{1,3}$ - Guorui Liu ${ }^{1,2} \cdot$ Xian Zhang ${ }^{1,2} \cdot$ Shujun Dong ${ }^{1,2}$. \\ Lirong Gao ${ }^{1,2}$. Yong Liang ${ }^{3}$
}

Received: 25 July 2016 / Accepted: 19 October 2016/Published online: 25 October 2016

(C) Springer-Verlag Berlin Heidelberg 2016

\begin{abstract}
Size-fractionated samples of urban particulate matter $(\mathrm{PM} ; \leq 1.0,1.0-2.5,2.5-10$, and $>10 \mu \mathrm{m})$ and gaseous samples were simultaneously obtained to study the distribution of polychlorinated biphenyls (PCBs) in the atmosphere in Beijing, China. Most recent investigations focused on the analysis of gaseous PCBs, and much less attention has been paid to the occurrence of PCBs among different PM fractions. In the present study, the gas-particle partitioning and sizespecific distribution of PCBs in atmosphere were investigated. The total concentrations (gas + particle phase fractions) of $\Sigma_{12}$ dioxin-like PCBs, $\Sigma_{7}$ indicator PCBs, and $\Sigma$ PCBs were 1.68 , 42.1 , and $345 \mathrm{pg} / \mathrm{m}^{3}$, respectively. PCBs were predominantly in the gas phase (86.8-99.0\% of the total concentrations). The gas-particle partition coefficients $\left(K_{p}\right)$ of PCBs were found to be a significant linear correlated with the subcooled liquid vapor pressures $\left(P_{\mathrm{L}}^{0}\right)\left(R^{2}=0.83, P<0.01\right)$. The slope $\left(m_{r}\right)$ implied that the gas-particle partitioning of PCBs was affected both by the mechanisms of adsorption and absorption. In addition, the concentrations of PCBs increased as the particle size decreased $(>10,2.5-10,1.0-2.5$, and $\leq 1.0 \mu \mathrm{m})$, with
\end{abstract}

Responsible editor: Constantini Samara

Electronic supplementary material The online version of this article (doi:10.1007/s11356-016-7936-y) contains supplementary material, which is available to authorized users.

Minghui Zheng

zhengmh@ rcees.ac.cn

1 State Key Laboratory of Environmental Chemistry and Ecotoxicology, Research Center for Eco-Environmental Sciences, Chinese Academy of Sciences, Beijing 100085, China

2 University of Chinese Academy of Sciences, Beijing 100049, China

3 Institute of Environment and Health, Jianghan University, Wuhan 430056, China most of the PCBs contained in the fraction of $\leq 1.0 \mu \mathrm{m}$ (53.4\% of the total particulate concentrations). Tetra-CBs were the main homolog in the air samples in the gas phase and PM fractions, followed by tri-CBs. This work will contribute to the knowledge of PCBs among different PM fractions and fill the gap of the size distribution of particle-bound dioxin-like PCBs in the air.

Keywords Polychlorinated biphenyls · Urban pollution · Atmospheric pollution · Particulate matter - Gas-particle partitioning $\cdot$ Size distribution

\section{Introduction}

Polychlorinated biphenyls (PCBs) are a group of compounds that were identified as priority persistent organic pollutants (POPs) in the initial list of chemicals included in the Stockholm Convention. Despite being banned in the 1970s, PCBs are always emitted from historical inputs and some unintentional industrial emissions (Liu et al. 2013b). Because they are stable and can undergo long-range atmospheric transport, they are ubiquitous in the environment, including at the polar regions (Hung et al. 2005; Pozo et al. 2006). PCBs have potential risks to humans and the environment, which have aroused great attention. Dioxin-like PCBs (dl-PCBs) have been demonstrated that they have immune toxicity, reproductive toxicity, and carcinogenic potency for organisms (Alves et al. 2016; Baars et al. 2004). Non-dioxinlike PCBs are also of concern because of their adverse impact on neurodevelopment (Yang et al. 2009).

Atmosphere is widely considered to be one of the primary pathways for the transport of PCBs, although the atmospheric burden of PCBs is relatively small compared with other environmental matrices (Piazza et al. 2013). The distribution of PCBs 
between the gas and particle phases plays a key role on the atmospheric fate (Gambaro et al. 2004). Gas- and particlephase PCBs will deplete or deposit in the atmosphere due to the processes of photochemical degradation reactions and wet or dry deposition, which will affect their long-range transport (Bidleman 1988; Mandalakis et al. 2009). In this context, evaluation of the gas-particle distribution of PCBs in the atmosphere has received worldwide attention in recent decades (Gregoris et al. 2014; Li et al. 2010; Yenisoy-Karakaş et al. 2012).

Many studies have emphasized the importance of airborne particulate matter (PM) in cardiopulmonary diseases and lung cancer (Loomis et al. 2013; Pope III et al. 2002), and the concentrations of organic pollutants in PM fractions are of great concern. Therefore, size-specific distribution plays a crucial role in the human health for determining where the inhalable particle-bound pollutants will deposit in the respiratory tract (Mandalakis et al. 2009). Furthermore, the distributions of organic pollutants in PM fractions can be used to identify the sources, behaviors, and environmental fate of pollutants. Consequently, the size-specific distribution of organic pollutants in the atmosphere has been widely investigated, including polycyclic aromatic hydrocarbons (PAHs) (Duan et al. 2007; Kiss et al. 1998), polychlorinated dibenzo- $p$-dioxins and dibenzofurans $(\mathrm{PCDD} / \mathrm{Fs})$ (Chuang et al. 2015; Oh et al. 2002; Zhang et al. 2016; Zhang et al. 2015), PCBs (Chen et al. 1996; Chrysikou et al. 2009), polychlorinated naphthalenes (PCNs) (Zhu et al. 2016), organochlorine pesticides (Landlová et al. 2014), polybrominated diphenyl ethers (Mandalakis et al. 2009), hexabromocyclododecane (Okonski et al. 2014), and tetrabromobisphenol A (Ni and Zeng 2013). Most of these studies showed that the pollutants tended to be concentrated in smaller particles. Differences in geographical location, meteorological conditions, and pollutant sources can result in considerable variations in particle size distribution. In terms of particle size distribution, PCBs are considered as model compounds for POPs. Chrysikou et al. found that indicator PCBs were predominantly concentrated in the PM fraction $(<0.95 \mu \mathrm{m})$ in the outdoor air (Chrysikou et al. 2009; Chrysikou and Samara 2009). Chen et al. (1996) reported that the particle size distribution of PCB homologs in different aerosols. However, the particle size distribution of dl-PCBs, the more toxic congeners among PCBs, is still unknown. Hence, a comprehensive investigation of size distribution of PCBs among PM fractions in the atmosphere is required.

As an international megacity with a population of over 20 million, atmospheric PM is a severe problem in Beijing, China, and its impact on public health has aroused widespread concern. The objective of this study was to monitor the gas and particle phase concentrations of PCBs, including dl$\mathrm{PCBs}$, indicator PCBs, and total PCBs (tri- to decachlorinated PCB homologs) in ambient air collected with a high-volume cascade impactor. In addition, the distribution of PCBs among PM fractions $(\leq 1.0,1.0-2.5,2.5-10$, and $>10 \mu \mathrm{m})$ was determined. Moreover, the gas-particle partitioning of atmospheric PCBs was studied. The PCB homolog and congener profiles in the gas phase and different PM fractions were also assessed. This study will improve knowledge of PCB levels and their distribution among different PM fractions in the air in China. This is the first report on the concentrations of dl-PCBs among PM fractions.

\section{Materials and methods}

\section{Sample collection}

Air samples for analysis of PCBs in the gas and particle phases were collected at the Beijing urban ecosystem research station $\left(116.34^{\circ} \mathrm{E}, 40.01^{\circ} \mathrm{N}\right)$ from October 2013 to June 2014. The sampling site was on the rooftop of a building and approximately $12 \mathrm{~m}$ above ground level. There were not main roads and obvious sources of pollution nearby. Each air sample was collected over 6 days using a KS-303 PM10/2.5/1.0 sampler (Kálmán System, Hungary). The atmospheric PM was separated into four fractions: $\leq 1.0,1.0-2.5,2.5-10$, and $>10 \mu \mathrm{m}$. The flow rate of the impactor was about $24 \mathrm{~m}^{3} / \mathrm{h}$. Approximately $3400 \mathrm{~m}^{3}$ of ambient air was first pumped through the quartz fiber filters of different sizes (Ahlstrom Munktell, Falun, Sweden) to retain the PM fractions and then through a polyurethane foam disk (Tisch Environmental, USA, $6.3 \mathrm{~cm}$ diameter $\times 7.6 \mathrm{~cm}$ length) to collect the gaseous PCBs. Seven groups of air samples, including the gas fraction and four PM fractions, were collected during the sampling period, giving a total of 35 samples for analysis (Electronic supplementary material (ESM) Table S1).

\section{Sample analysis}

Twelve dl-PCB congeners (CB-77, CB-81, CB-105, CB-114, CB-118, CB-123, CB-126, CB-156, CB-157, CB-167, CB169 , and CB-189), seven indicator PCBs (CB-28, CB-52, CB-101, CB-118, CB-138, CB-153, and CB-180), and tri- to deca-chlorinated PCB homologs ( $\mathrm{PCB}$ s) were analyzed according to a modified version of US EPA Method 1668B (Wang et al. 2015). Each air sample was spiked with $1 \mathrm{ng}$ of ${ }^{13} \mathrm{C}_{12}$-labeled PCBs internal standard with known concentrations (68B-LCS, Wellington Laboratories, Guelph, Canada) and then extracted with dichloromethane and hexane $(1: 1$, $v / v)$ using an accelerated solvent extractor. The extracts were cleaned up by acid silica gel columns, multilayer silica gel columns and followed by activated carbon columns. Finally, the extracts were evaporated to approximately $20 \mu \mathrm{L}$, and $1 \mathrm{ng}$ of ${ }^{13} \mathrm{C}_{12}$-labeled PCB recovery standard with known concentrations (68B-IS, Wellington Laboratories) was added. 
The target PCBs were determined using an Agilent 6890 gas chromatograph coupled with a Waters Autospec Ultima high-resolution mass spectrometer, operating in a positive electron impact (EI+) mode at the selected ion monitoring mode with a resolving power greater than 10,000 . A DB$5 \mathrm{~ms}$ capillary column $(60 \mathrm{~m} \times 0.25 \mathrm{~mm}$ i.d. $\times 0.25 \mu \mathrm{m}$, Agilent Technologies, Santa Clara, CA) was used for the separation of PCB congeners. The electron energy and source temperature were $35 \mathrm{eV}$ and $270{ }^{\circ} \mathrm{C}$, respectively. The transfer-line temperature was $270{ }^{\circ} \mathrm{C}$.

The range for labeled PCB recoveries in this study was $34.0-135 \%$. The limit of detection (signal-to-noise ratio of $>3: 1)$ range for PCBs was $0.00880-2.17 \mathrm{fg} / \mathrm{m}^{3}$. One field blank and four laboratory blanks were conducted for quality control. Blank values were below the limit of detection.

\section{Results and discussion}

\section{Concentrations and partitioning of gas-particle phase PCBs}

The concentrations of 12 dl-PCBs, seven indicator PCBs, and $\triangle$ PCBs were measured in the air samples (Table 1). The total average concentrations (gas + particle phase fractions) of $\Sigma_{12}$ dl-PCBs, $\Sigma_{7}$ indicator PCBs, and $\Sigma$ PCBs were $1.68,42.1$, and $306 \mathrm{pg} / \mathrm{m}^{3}$, respectively. The dl-PCB concentrations were much lower than those of indicator PCBs. Compared with previous date from other urban sites, results showed that the PCB concentrations observed in the atmosphere in this study were similar to those reported in Tarragona (Spain) (Vilavert et al. 2014), lower than in those in Taiwan (Chen et al. 1996), Chicago (Rodenburg and Meng 2013), and an industrial city in Italy (Colombo et al. 2013), and higher than those measured in Dalian, China (Xu et al. 2013). The average toxic equivalent (TEQ) values of PCBs among different fractions in the atmosphere are also shown in Table 1. The total dioxin-like toxicity was $8.78 \mathrm{fg} \mathrm{WHO}-\mathrm{TEQ} / \mathrm{m}^{3}$ in the atmosphere, which was similar to that reported for Venice (Gregoris et al. 2014).

PCBs in the atmosphere appeared to be present mainly in the gas phase, with the gaseous PCB concentration ranging from 62.4 to $524 \mathrm{pg} / \mathrm{m}^{3}$. By comparison, the concentration of PCBs associated with the particle phase ranged from 3.97 to $42.8 \mathrm{pg} / \mathrm{m}^{3}$. The average gas/ particle ratio calculated for the air samples was 34.5, which was similar to the ratios reported in earlier studies (Gregoris et al. 2014; Yenisoy-Karakaş et al. 2012). The gas-particle partitioning of PCBs is affected by meteorological factors (e.g., temperature, humidity, and pressure) and the chemical properties of the compounds (e.g., molecular weight and vapor pressure) (Hassan and Khoder 2012). PCBs are semi-volatile POPs, which favor their volatilization from the particle phase to the gas phase.

The gas-particle partition coefficient $K_{p}\left(\mathrm{~m}^{3} / \mu \mathrm{g}\right)$ can be calculated with Eq. (1) to describe the distribution of PCBs.

$K_{p}=(F / T S P) / A$

where $F$ and $A$ are the concentrations $\left(\mathrm{pg} / \mathrm{m}^{3}\right)$ of the analyte in the particle and gas phases, respectively, and TSP is the total suspended particle concentration $\left(\mu \mathrm{g} / \mathrm{m}^{3}\right)$.

There is a linear relationship between $\log K_{p}$ and the logarithm of the subcooled liquid vapor pressure $\left(P_{\mathrm{L}}{ }^{0}\right)$ (Pankow 1994), as shown in the following equation:

$\log K_{p}=m_{r} \log P_{\mathrm{L}}^{0}+\mathrm{b}_{\mathrm{r}}$

where $m_{r}$ is the slope of the trend line and $b_{r}$ is the $y$-intercept.

It was found that at equilibrium, the slope $\left(m_{r}\right)$ should be close to -1 (Pankow 1994). However, slopes that deviate from

Table 1 Concentrations of PCBs in different fractions in the atmosphere

\begin{tabular}{|c|c|c|c|c|c|c|c|}
\hline & \multicolumn{4}{|l|}{ Particle size $(\mu \mathrm{m})$} & \multirow[t]{2}{*}{ Particles } & \multirow[t]{2}{*}{ Gas } & \multirow[t]{2}{*}{ Total (gas + particle) } \\
\hline & $>10$ & $2.5-10$ & $1.0-2.5$ & $\leq 1.0$ & & & \\
\hline$\Sigma_{12}$ dl-PCBs & $0.0200 \pm 0.144$ & $0.0324 \pm 0.0267$ & $0.0486 \pm 0.0341$ & $0.213 \pm 0.178$ & $0.314 \pm 0.246$ & $1.37 \pm 0.786$ & $1.68 \pm 0.707$ \\
\hline Range & $0.00201-0.0456$ & $0.00756-0.0814$ & $0.00952-0.103$ & $0.0248-0.542$ & $0.0518-0.772$ & $0.359-2.66$ & $0.655-2.75$ \\
\hline$\Sigma_{7}$ indicator PCBs & $0.113 \pm 0.0649$ & $0.145 \pm 0.104$ & $0.178 \pm 0.137$ & $0.582 \pm 0.622$ & $1.02 \pm 0.904$ & $41.1 \pm 19.8$ & $42.1 \pm 19.7$ \\
\hline Range & $0.00800-0.209$ & $0.0143-0.351$ & $0.0544-0.472$ & $0.162-1.94$ & $0.303-2.97$ & $8.67-67.2$ & $8.97-67.7$ \\
\hline$\Sigma \mathrm{PCBs}$ & $1.05 \pm 0.635$ & $1.69 \pm 1.47$ & $3.29 \pm 3.07$ & $7.43 \pm 8.64$ & $13.5 \pm 13.4$ & $292 \pm 157$ & $306 \pm 159$ \\
\hline Range & $0.488-1.87$ & $0.138-4.67$ & $0.585-9.55$ & $1.41-26.7$ & $3.97-42.8$ & $62.4-524$ & $66.5-537$ \\
\hline $\mathrm{WHO}_{2005}-\mathrm{TEQ}\left(\mathrm{fg} / \mathrm{m}^{3}\right)$ & $0.156 \pm 0.116$ & $0.273 \pm 0.250$ & $0.513 \pm 0.405$ & $2.43 \pm 2.15$ & $3.37 \pm 2.85$ & $5.41 \pm 3.41$ & $8.78 \pm 3.37$ \\
\hline Range $\left(\mathrm{fg} / \mathrm{m}^{3}\right)$ & $0.0188-0.353$ & $0.0582-0.696$ & $0.0670-1.05$ & $0.225-6.05$ & $0.418-8.15$ & $1.33-9.50$ & $3.99-12.6$ \\
\hline
\end{tabular}

Concentrations are expressed in $\mathrm{pg} / \mathrm{m}^{3} \pm$ standard deviation $(n=7)$ 
-1 have been found in the field monitoring and a number of factors can result in the deviations of the value (Goss and Schwarzenbach 1998; Simcik et al. 1998).

$P_{\mathrm{L}}^{0}$ can be calculated with Eq. (3) (Offenberg and Baker 1999; Paasivirta et al. 1999), as follows:

$\log P_{\mathrm{L}}^{0}=m_{\mathrm{L}}(1 / T)+b_{\mathrm{L}}$

where $T$ is the ambient temperature, and $m_{\mathrm{L}}$ and $b_{\mathrm{L}}$ are constants related to the properties of PCBs. The values of $m_{\mathrm{L}}$ and $b_{\mathrm{L}}$ for the $\mathrm{PCB}$ congeners in this study were given by Falconer and Bidleman (1994).

In the present study, there was a strong relationship $\left(R^{2}=0.83\right)$ between $\log K_{p}$ and $\log P_{\mathrm{L}}^{0}$ (Fig. 1) for the urban air samples, and the slope $(-0.904)$ was between -1.0 and -0.6 . These results implied that the gas-particle partitioning of PCBs in the atmosphere did not approach equilibrium but was relatively close to equilibrium. This may be influenced by the traffic and other sources of pollution. The slope also indicated that the gas-particle partitioning of PCBs was affected both by the mechanisms of adsorption and absorption (Goss and Schwarzenbach 1998).

\section{Size-specific distribution of PCBs in the PM fractions}

In this study, four particle-bound fractions were analyzed for the concentrations of PCBs (Table 1). The $\Sigma$ PCB concentrations varied among the $\mathrm{PM}$ fractions and increased in the following order: $>10,2.5-10,1.0-2.5$, and $\leq 1.0 \mu \mathrm{m}$ (Fig. 2). The concentrations of dl-PCB congeners and indicator PCB congeners showed similar distributions (Table 1). Indicator PCBs were found to be mainly associated with the smallest PM fraction $(<0.95 \mu \mathrm{m})$ in the outdoor air (Chrysikou et al. 2009; Chrysikou and Samara 2009). In agreement with these studies, we found that PCBs ( $\Sigma$ PCBs, $\Sigma$ dl-PCBs, or $\Sigma$ indicator PCBs) were mainly concentrated in the smallest PM

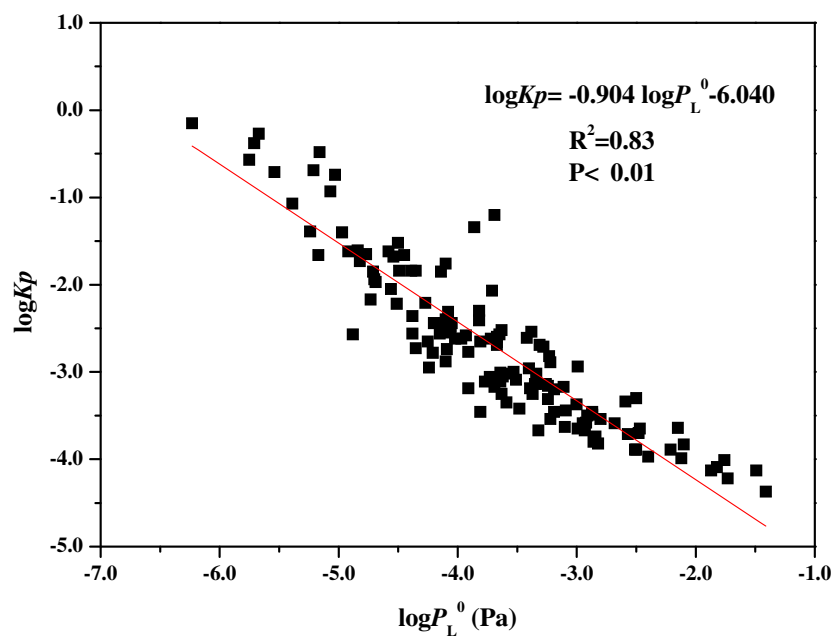

Fig. 1 Regression of $\log K_{p}$ versus $\log P_{\mathrm{L}}{ }^{0}$ for the PCBs fraction $(\leq 1.0 \mu \mathrm{m})$ collected in this study. However, another study found industrial aerosols were mainly associated with fine PM fraction $(<2.5 \mu \mathrm{m})$, while at an urban site, PCBs were predominately present in coarse PM fraction $(>2.5 \mu \mathrm{m})$ (Chen et al. 1996), which differed from the results in this study.

Among the four PM fractions, submicron PMs $\left(\mathrm{PM}_{1.0}\right)$ were the main contributors (average $53.4 \%$ ) to PCBs and $66.5-95.4 \%$ of $\Sigma$ PCBs was associated with fine PMs $\left(\mathrm{PM}_{2.5}\right)$. These results indicated that $\Sigma \mathrm{PCBs}$ may be inclined to adsorb on the finer PMs. Li et al. pointed out that fine PMs have larger absorption capacity than coarse PMs due to their larger surface areas, which verified that fine PMs could adsorb more PCBs than coarse PMs (Li and Davis 1996; Liu et al. 2013a).

The mean-normalized size distribution of PCBs among the four PM fractions was analyzed (Fig. 3). Normalized histograms of $\mathrm{d} C / \mathrm{d} \log D_{p}$ against $D_{p}$, where $\mathrm{d} C$ is the concentration of PCBs in each PM fraction and $D_{p}$ is the aerodynamic diameter, have been used for investigating the distribution of PCBs among different PM fractions (Chrysikou et al. 2009; Chrysikou and Samara 2009). In this study, it was evident that tri-, tetra-, and deca-CB homologs exhibited the same unimodal distribution patterns with a peak in the PM fraction of $1.0-2.5 \mu \mathrm{m}$. The remaining homolog groups (penta- to nano-CBs) were also enriched in the PM fraction of $\leq 1.0 \mu \mathrm{m}$. Similarly, dl-PCB congeners and indicator PCB congeners also showed unimodal distribution patterns (ESM Figs. S1 and S2).

\section{Homolog and congener profiles of PCBs in the gas and particle phases}

ESM Fig. S3 shows the homolog profiles of PCBs (gas + particle phase fractions), based on the degree of chlorination (tri to deca). The percentage contributions of the homologs to

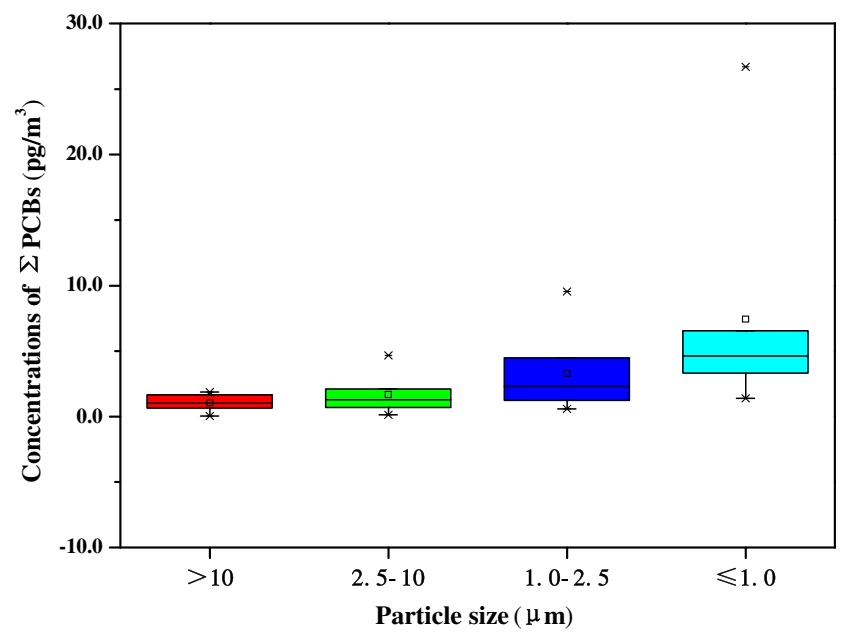

Fig. 2 Distribution of $\sum \mathrm{PCBs}$ in different particulate matter fractions 

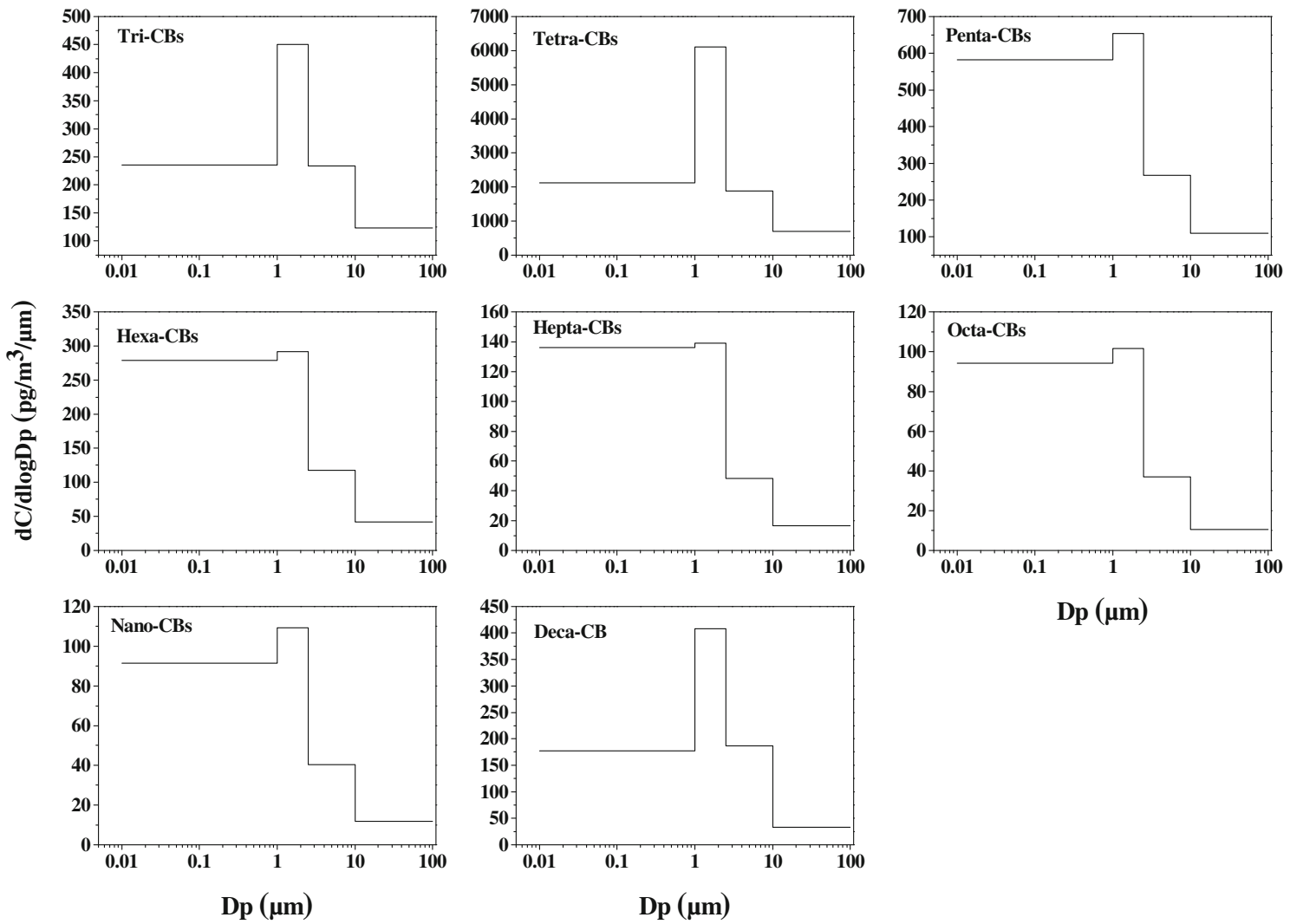

Fig. 3 Mean-normalized size-specific distribution of PCB homologs (tri to deca) in the collected particulate matter fractions

the total PCB concentrations ( $\triangle \mathrm{PCBs}$ ) were in the following order: tetra-CBs $(68.9 \%)>$ tri-CBs $(21.2 \%)>$ penta-CBs (7.44\%). The homolog profile was similar in both the gas and particle phases (Fig. 4). In both phases, the dominant homolog was tetra-CBs, which accounted for $69.0 \%$ (gas phase) and $63.0 \%$ (particle phase) of $\Sigma$ PCBs. The lower chlorinated PCBs can be more likely to evaporate into the atmosphere than higher chlorinated ones, which attributed to their higher vapor pressure (Wania and Mackay 1996). The pattern of PCBs found in Beijing in the present study, with tetra-CBs as the primary homolog, is similar to previous studies (Gregoris et al. 2014).

As expected, the gas-particle distribution of the PCBs (ESM Fig. S4) showed the typical pattern with lower
Fig. 4 Comparison of concentrations $\left(\mathrm{pg} / \mathrm{m}^{3}\right)$ of $\mathrm{PCB}$ homologs (tri to deca) in the gas and particle phases

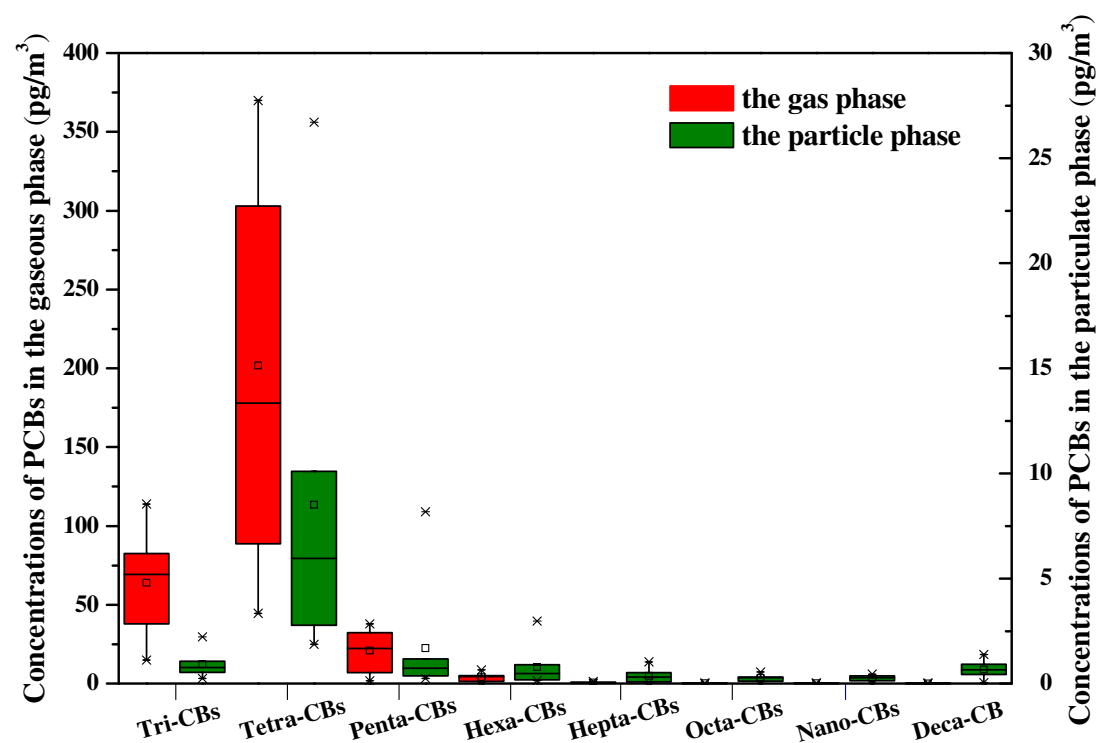


(a)

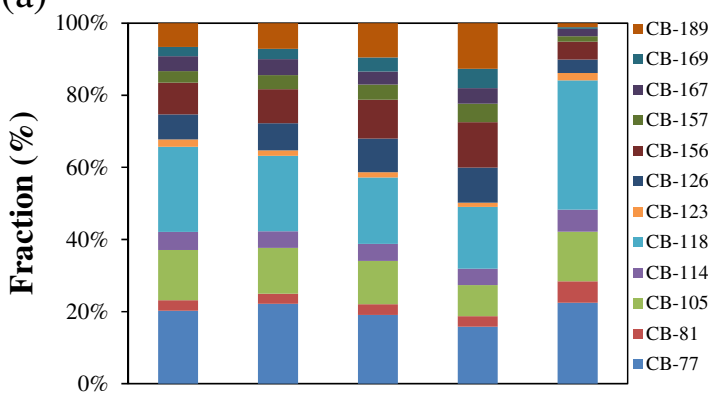

(c)

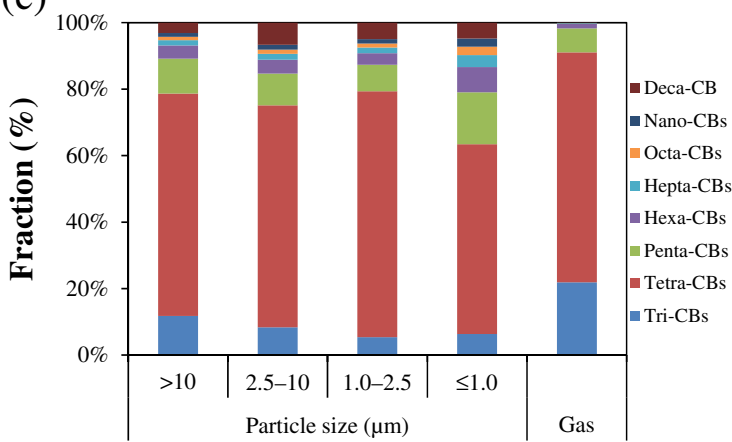

(b)

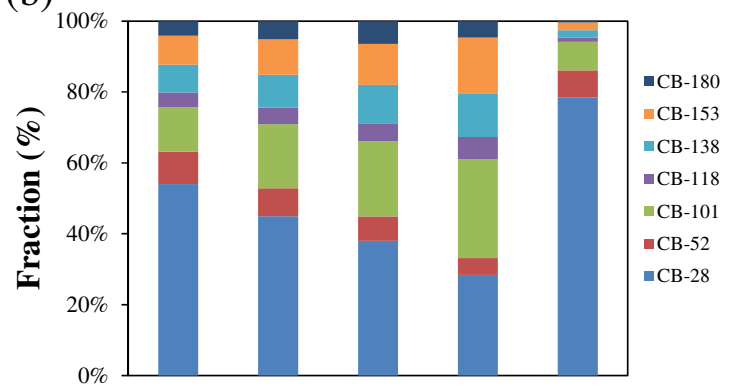

(d)

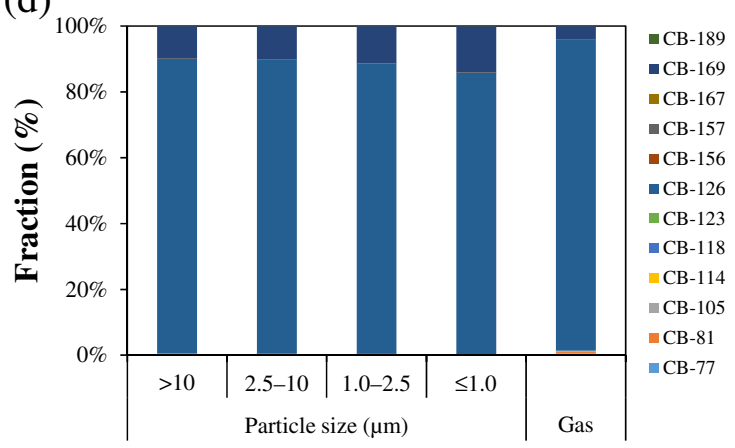

Fig. 5 Congener profiles of dl-PCBs (a) and indicator PCBs (b), homolog profiles of PCBs (c), and TEQ profiles (d) in the gas phase and particulate matter fractions

chlorinated homologs concentrated in the gas phase. The triCBs to hepta-CBs in the gas phase accounted for 59.9-98.6\% of $\Sigma \mathrm{PCB}$ concentrations. Higher chlorinated homologs (e.g., octa-CBs to deca-CBs) tended to be in the particle phase, accounting for about 59.9-86.1\% of $\Sigma \mathrm{PCB}$ concentrations. The proportion of PCB homologs (tri-CBs to deca-CBs) in the gas phase generally decreased as the degree of chlorination increased, and the proportion in the particle phase increased at the same time. The strong correlation between PCB distribution and molecular weight is in good agreement with previous studies (Gregoris et al. 2014). In general, low molecular weight PCBs are more volatile than high ones, and they can be easier to transfer to the gas phase, while the opposite situation occurs for high molecular weight PCBs.

The profiles of PCBs in the gas phase and four PM fractions were compared (Fig. 5). The distribution in the gas phase was very similar to that in the PM fractions. The congener profiles of dl-PCBs and indicator PCBs, and the homolog profiles of PCBs in the air samples were consistent with those found in previous studies (Wu et al. 2011). The dl-PCB congener profiles in the atmosphere (Fig. 5a) showed two dominant congeners (CB-118 and CB-77), which accounted for $33.0-58.3 \%$ of $\Sigma_{12}$ dl-PCBs. These were followed by CB105 and CB-156. The indicator PCB profiles in the atmosphere (Fig. 5b) showed that CB-28 was the most abundant indicator PCB in the gas phase ( $78.4 \%$ of $\Sigma_{7}$ indicator PCBs). The PM fractions had a more complex distribution of congeners, together CB-28 and CB-101 accounted for 56.3-66.4\% of total indicator PCBs in the particle phase. The congener concentrations of indicator PCBs generally decreased with increasing chlorination level. Tetra-CBs, which have a low degree of chlorination, were the most abundant homologs both in the gas phase and in the four PM fractions (Fig. 5c). In the TEQ profiles of dl-PCBs (Fig. 5d), CB-126 was the most abundant congener in the atmosphere. Because of the high TEF value, CB-126 accounted for 85.6-94.4\% of the total TEQ. The variations in TEQ can be closely related to the CB-126 concentration, which greatly affects the TEQ value (Wu et al. 2011).

\section{Conclusion}

In the present study, the levels, gas-particle partitioning, and size-specific distribution of PCBs were investigated in the urban atmosphere in Beijing, China. PCBs were found predominately in the gas phase. The gas-particle partitioning of PCBs showed a typical pattern, with lower chlorinated homologs mainly concentrated in the gas phase and higher chlorinated homologs in the particle phase. The slope for the relationship between $K_{p}$ and $P_{\mathrm{L}}{ }^{0}$ for PCBs indicated that both adsorption and absorption affected the gas-particle partitioning. In addition, the concentrations of PCBs increased as the particle size decreased and they were mainly associated with the smallest particles $(\leq 1.0 \mu \mathrm{m})$. These data will contribute to the understanding of gas-particle partitioning and particle size distribution of PCBs in the atmosphere. 
Acknowledgments This work was supported by the National Natural Science Foundation of China (Nos. 21361140359, 91543108, and 21321004) and the Strategic Priority Research Program of the Chinese Academy of Sciences (No. XDB14020000).

\section{References}

Alves C, Vicente A, Gomes J, Nunes T, Duarte M, Bandowe B (2016) Polycyclic aromatic hydrocarbons (PAHs) and their derivatives (oxygenated-PAHs, nitrated-PAHs and azaarenes) in size-fractionated particles emitted in an urban road tunnel. Atmos Res 180:128-137

Baars A, Bakker M, Baumann R, Boon P, Freijer J, Hoogenboom L, Hoogerbrugge R, Van Klaveren J, Liem A, Traag W (2004) Dioxins, dioxin-like PCBs and non-dioxin-like PCBs in foodstuffs: occurrence and dietary intake in The Netherlands. Toxicol Lett 151: $51-61$

Bidleman TF (1988) Atmospheric processes - wet and dry deposition of organic compounds are controlled by their vapor-particle partitioning. Environ Sci Technol 22:361-367

Chen SJ, Hsieh LT, Hwang PS (1996) Concentration, phase distribution, and size distribution of atmospheric polychlorinated biphenyls measured in southern Taiwan. Environ Int 22:411-423

Chrysikou LP, Samara CA (2009) Seasonal variation of the size distribution of urban particulate matter and associated organic pollutants in the ambient air. Atmos Environ 43:4557-4569

Chrysikou LP, Gemenetzis PG, Samara CA (2009) Wintertime size distribution of polycyclic aromatic hydrocarbons (PAHs), polychlorinated biphenyls (PCBs) and organochlorine pesticides (OCPs) in the urban environment: street- vs rooftop-level measurements. Atmos Environ 43:290-300

Chuang KY, Lai CH, Peng YP, Yen TY (2015) Characteristics of particlebound polychlorinated dibenzo- $p$-dioxins and dibenzofurans $(\mathrm{PCDD} / \mathrm{Fs})$ in atmosphere used in carbon black feeding process at a tire manufacturing plant. Environ Sci Pollut R 22:19451-19460

Colombo A, Benfenati E, Bugatti SG, Lodi M, Mariani A, Musmeci L, Rotella G, Senese V, Ziemacki G, Fanelli R (2013) PCDD/Fs and PCBs in ambient air in a highly industrialized city in Northern Italy. Chemosphere 90:2352-2357

Duan J, Bi X, Tan J, Sheng G, Fu J (2007) Seasonal variation on size distribution and concentration of PAHs in Guangzhou city, China. Chemosphere 67:614-622

Falconer RL, Bidleman TF (1994) Vapor pressures and predicted particle/ gas distributions of polychlorinated biphenyl congeners as functions of temperature and ortho-chlorine substitution. Atmos Environ 28: 547-554

Gambaro A, Manodori L, Moret I, Capodaglio G, Cescon P (2004) Determination of polychlorobiphenyls and polycyclic aromatic hydrocarbons in the atmospheric aerosol of the Venice Lagoon. Anal Bioanal Chem 378:1806-1814

Goss KU, Schwarzenbach RP (1998) Gas/solid and gas/liquid partitioning of organic compounds: critical evaluation of the interpretation of equilibrium constants. Environ Sci Technol 32:20252032

Gregoris E, Argiriadis E, Vecchiato M, Zambon S, De Pieri S, Donateo A, Contini D, Piazza R, Barbante C, Gambaro A (2014) Gas-particle distributions, sources and health effects of polycyclic aromatic hydrocarbons (PAHs), polychlorinated biphenyls (PCBs) and polychlorinated naphthalenes (PCNs) in Venice aerosols. Sci Total Environ 476:393-405

Hassan SK, Khoder M (2012) Gas-particle concentration, distribution, and health risk assessment of polycyclic aromatic hydrocarbons at a traffic area of Giza, Egypt. Environ Monit Assess 184:3593-3612
Hung H, Lee SC, Wania F, Blanchard P, Brice K (2005) Measuring and simulating atmospheric concentration trends of polychlorinated biphenyls in the Northern Hemisphere. Atmos Environ 39:6502-6512

Kiss G, Varga-Puchony Z, Rohrbacher G, Hlavay J (1998) Distribution of polycyclic aromatic hydrocarbons on atmospheric aerosol particles of different sizes. Atmos Res 46:253-261

Landlová L, Čupr P, Franců J, Klánová J, Lammel G (2014) Composition and effects of inhalable size fractions of atmospheric aerosols in the polluted atmosphere: part I. PAHs, PCBs and OCPs and the matrix chemical composition. Environ Sci Pollut R 21:6188-6204

Li WG, Davis EJ (1996) Aerosol evaporation in the transition regime. Aerosol Sci Technol 25:11-21

Li Y, Wang P, Ding L, Li X, Wang T, Zhang Q, Yang H, Jiang G, Wei F (2010) Atmospheric distribution of polychlorinated dibenzo- $p$-dioxins, dibenzofurans and dioxin-like polychlorinated biphenyls around a steel plant area, northeast China. Chemosphere 79:253-258

Liu C, Shi SS, Weschler C, Zhao B, Zhang YP (2013a) Analysis of the dynamic interaction between SVOCs and airborne particles. Aerosol Sci Technol 47:125-136

Liu G, Zheng M, Cai M, Nie Z, Zhang B, Liu W, Du B, Dong S, Hu J, Xiao K (2013b) Atmospheric emission of polychlorinated biphenyls from multiple industrial thermal processes. Chemosphere 90:2453-2460

Loomis D, Grosse Y, Lauby-Secretan B, Ghissassi FE, Bouvard V, Benbrahim-Tallaa L, Guha N, Baan R, Mattock H, Straif K (2013) The carcinogenicity of outdoor air pollution. The Lancet Oncol 14: $1262-1263$

Mandalakis M, Besis A, Stephanou EG (2009) Particle-size distribution and gas/particle partitioning of atmospheric polybrominated diphenyl ethers in urban areas of Greece. Environ Pollut 157: $1227-1233$

Ni H, Zeng H (2013) HBCD and TBBPA in particulate phase of indoor air in Shenzhen, China. Sci Total Environ 458:15-19

Offenberg JH, Baker JE (1999) Aerosol size distributions of polycyclic aromatic hydrocarbons in urban and over-water atmospheres. Environ Sci Technol 33:3324-3331

Oh JE, Chang YS, Kim EJ, Lee DW (2002) Distribution of polychlorinated dibenzo- $p$-dioxins and dibenzofurans $(\mathrm{PCDD} / \mathrm{Fs}$ ) in different sizes of airborne particles. Atmos Environ 36:5109-5117

Okonski K, Degrendele C, Melymuk L, Landlova L, Kukucka P, Vojta S, Kohoutek J, Cupr P, Klanova J (2014) Particle size distribution of halogenated flame retardants and implications for atmospheric deposition and transport. Environ Sci Technol 48:14426-14434

Paasivirta J, Sinkkonen S, Mikkelson P, Rantio T, Wania F (1999) Estimation of vapor pressures, solubilities and Henry's law constants of selected persistent organic pollutants as functions of temperature. Chemosphere 39:811-832

Pankow JF (1994) An absorption model of gas/particle partitioning of organic compounds in the atmosphere. Atmos Environ 28:185-188

Piazza R, Gambaro A, Argiriadis E, Vecchiato M, Zambon S, Cescon P, Barbante C (2013) Development of a method for simultaneous analysis of PCDDs, PCDFs, PCBs, PBDEs, PCNs and PAHs in Antarctic air. Anal Bioanal Chem 405:917-932

Pope CA III, Burnett RT, Thun MJ, Calle EE, Krewski D, Ito K, Thurston GD (2002) Lung cancer, cardiopulmonary mortality, and long-term exposure to fine particulate air pollution. JAMA 287:1132-1141

Pozo K, Harner T, Wania F, Muir DC, Jones KC, Barrie LA (2006) Toward a global network for persistent organic pollutants in air: results from the GAPS study. Environ Sci Technol 40:4867-4873

Rodenburg LA, Meng Q (2013) Source apportionment of polychlorinated biphenyls in Chicago air from 1996 to 2007. Environ Sci Technol 47:3774-3780

Simcik MF, Franz TP, Zhang H, Eisenreich SJ (1998) Gas-particle partitioning of PCBs and PAHs in the Chicago urban and adjacent coastal atmosphere: states of equilibrium. Environ Sci Technol 32: $251-257$ 
Vilavert L, Nadal M, Schuhmacher M, Domingo JL (2014) Seasonal surveillance of airborne $\mathrm{PCDD} / \mathrm{Fs}, \mathrm{PCBs}$ and $\mathrm{PCNs}$ using passive samplers to assess human health risks. Sci Total Environ 466-467: 733-740

Wang M, Hou M, Zhao K, Li H, Han Y, Liao X, Chen X, Liu W (2015) Removal of polychlorinated biphenyls by desulfurization and emissions of polychlorinated biphenyls from sintering plants. Environ Sci Pollut R 23:7369-7375

Wania F, Mackay D (1996) Peer reviewed: tracking the distribution of persistent organic pollutants. Environ Sci Technol 30:390A-396A

Wu J, Teng M, Gao L, Zheng M (2011) Background air levels of polychlorinated biphenyls in China. Sci Total Environ 409:18181823

Xu Q, Zhu XH, Henkelmann B, Schramm K-W, Chen J, Ni Y, Wang W, Pfister G, Mu J, Qin S, Li Y (2013) Simultaneous monitoring of PCB profiles in the urban air of Dalian, China with active and passive samplings. J Environ Sci 25:133-143

Yang D, Kim KH, Phimister A, Bachstetter AD, Ward TR, Stackman RW, Mervis RF, Wisniewski AB, Klein SL, Kodavanti PRS (2009)
Developmental exposure to polychlorinated biphenyls interferes with experience-dependent dendritic plasticity and ryanodine receptor expression in weanling rats. Environ Health Persp 117:426

Yenisoy-Karakaş S, Öz M, Gaga EO (2012) Seasonal variation, sources, and gas/particle concentrations of PCBs and OCPs at high altitude suburban site in Western Black Sea Region of Turkey. J Environ Monitor 14:1365-1374

Zhang X, Zhu QQ, Dong SJ, Zhang HX, Wang XK, Wang M, Gao LR, Zheng MH (2015) Particle size distributions of PCDD/Fs and $\mathrm{PBDD} / \mathrm{Fs}$ in ambient air in a suburban area in Beijing, China. Aerosol Air Qual Res 15:1933-1943

Zhang X, Zheng M, Liu G, Zhu Q, Dong S, Zhang H, Wang X, Xiao K, Gao L, Liu W (2016) A comparison of the levels and particle size distribution of lower chlorinated dioxin/furans (mono- to trichlorinated homologues) with those of tetra- to octa-chlorinated homologues in atmospheric samples. Chemosphere 151:55-58

Zhu Q, Zhang X, Dong S, Gao L, Liu G, Zheng M (2016) Gas and particle size distributions of polychlorinated naphthalenes in the atmosphere of Beijing, China. Environ Pollut 212:128-134 